\title{
Donación de órganos, una perspectiva antropológica
}

\section{Esperanza Vélez Vélez}

Unidad de Diálisis. Fundación Jiménez Díaz-Capio. Madrid

\section{Resumen}

La aproximación antropológica de la donación de órganos tiene como finalidad captar cómo se estructura la situación sociocultural de la donación y extraer los lazos de significación.

El presente artículo pretende analizar la donación de órganos desde el enfoque amplio que la antropología permite, un enfoque que tiene presente a los actores implicados desde una perspectiva individual y desde la perspectiva social y cultural. Aunque la donación es un hecho físicamente individual, es básicamente un acto social, colectivo. Se hace por y para la colectividad.

Utilizando una metodología cualitativa narrativa se recogieron las impresiones sobre el fenómeno de la donación entre familiares de pacientes y estudiantes de enfermería y psicología. Se analiza el concepto de donación, la donación como acto individual y hecho social, los distintos motivos que condicionan las diferentes representaciones de la donación, entre otros.

Mayor información y un trato más sensible hacia el donante apuntan como factores facilitadores y de compensación social en la donación de órganos.

\author{
Correspondencia: \\ Esperanza Vélez \\ Unidad de Diálisis \\ Fundación Jiménez Díaz-Capio \\ Avda Reyes Católicos 2 \\ 28040 Madrid \\ Correo electrónico: evelez@fjd.es
}

Palabras clave:

DONACIÓN

ACTO SOCIAL

MOTIVACIONES

\section{Organ donation - an anthropological perspective}

\section{Abstract}

The anthropological approach to organ donation has as a main goal to capture how the sociocultural aspect of donation is structured and to bring about the meaning of it.

The present paper tries to analyze organ donation from the anthropologic perspective and the broad focus for it allowed, an approach that keeps in mind the actors involved not just from the individual perspective but from the social and cultural one. Even though organ donation is a physically individual act, it is basically a social and collective event. It is done by and for the collectivity.

Using a qualitative narrative methodology, the impressions about donation were gathered among family patients and nursing and psychology students. Concept of donation, donation as an individual act and a social event, different motives conditioning the distinct cognitive representation of donation, among others, are analyzed.

More information and a more sensitive treatment toward donors point out as social compensation and facilitator factors in organ donation. 
Key words: DONATION SOCIAL ACT MOTIVATION

\section{Introducción}

La donación de órganos constituye la base fundamental del trasplante como tratamiento óptimo de los pacientes con insuficiencia hepática, cardiaca 0 renal; un tratamiento que constituye un ejemplo de moderna tecnología sanitaria y cuya eficacia y capacidad para salvar vidas o mejorar sensiblemente el grado de rehabilitación de estos pacientes está fuera de toda duda.

En el presente trabajo analizaré el fenómeno de la donación de órganos desde la perspectiva antropológica. Los trabajos realizados desde la medicina se centran fundamentalmente en el aspecto científico del fenómeno donación/trasplante. Desde la psicología encontramos estudios descriptivos de los donantes de órganos y de los familiares, y estudios psicosociales que analizan actitudes hacia la donación, motivación, etc. También, aunque en menor medida, encontramos algunos trabajos que analizan las vías para potenciar la donación en la sociedad y desarrollo de programas de intervención comunitaria encaminados al incremento del número de donaciones.

Es mi intención analizar la donación de órganos desde el enfoque amplio que la antropología permite, un enfoque que tiene presente a los actores implicados desde una perspectiva individual y desde la perspectiva social y cultural. La aproximación antropológica de la donación de órganos tiene como finalidad captar cómo se estructura la situación sociocultural de la donación y extraer los lazos de significación.

Aunque la donación es un hecho físicamente individual, es básicamente un acto social, colectivo. Se hace por y para la colectividad.

Este trabajo forma parte de un proyecto más amplio que analiza los significados y representaciones de la insuficiencia renal crónica y sus distintas formas de tratamiento. Utilizando una metodología cualitativa narrativa, se recogieron las impresiones sobre el fenómeno de la donación entre familiares de pacientes y estudiantes de enfermería y psicología. El trabajo de campo se realizó en Madrid. Además, el estudio refleja mi experiencia como enfermera de diálisis con 25 años al cuidado de pacientes renales; una experiencia que me ha permitido mantener un estrecho contacto con pacientes necesitados de un "regalo de vida", con donantes potenciales y con donantes vivos que ya han materializado el hecho de la donación. También incluye el análisis de material diverso sobre el tema.

\section{Concepto de donación}

En distintas sociedades, épocas y contextos los individuos o grupos sociales han utilizado la donación, en toda su dimensión, como medio básico indispensable para producir y reproducir las estructuras básicas de la sociedad. Pero a medida que las sociedades se desarrollan, la influencia del mercado se extiende sobre la producción, y los intercambios y el Estado crean estructuras que gestionan las desigualdades.

Con el paso del tiempo, y centrándonos en nuestra cultura occidental, el don sigue existiendo pero liberado de la responsabilidad de tener que producir y reproducir relaciones sociales fundamentales y comunes a todos los miembros de la Sociedad. Se ha convertido objetivamente en una cuestión ante todo subjetiva, personal e individual. Es la expresión y el instrumento de relaciones personales que se sitúan más allá del mercado y del Estado. Se supone que el Estado representa a todos los sectores de la sociedad y tiene la misión de gobernar de tal modo que los conflictos de intereses y las contradicciones que se desarrollan entre algunos de ellos no les impidan reproducirse como un todo, y aun menos arrojen fuera de ese todo a una parte de la sociedad. Ahora bien, en la actualidad, el Estado pierde protagonismo no sólo en el control de la economía, también en la sanidad y en la educación. Es en este contexto donde el don "generoso" (don sin retorno), en el que se encuadra la donación de órganos, se solicita nuevamente para ayudar a resolver problemas de Sociedad. Así, el don se ha convertido de nuevo en una condición objetiva, socialmente necesaria, de la reproducción de la sociedad ${ }^{1}$. 
En el caso concreto de la donación de órganos, es la sociedad la que, representada por la institución sanitaria, demanda la donación de órganos mediante sus campañas de captación, pide, reclama ayuda para su subsistencia "puesto que quien está en peligro es un miembro de la sociedad"/2. Una demanda que se ha vuelto mediática y burocrática y utiliza los medios de comunicación para sensibilizar a la opinión, para conmover e impresionar e invocar la generosidad de cada uno de nosotros, la solidaridad que debería reinar en una sociedad abstracta situada más allá de las diferencia de cultura, de clase o de casta, de lengua y de identidad.

\section{Donación de Órganos- acto individual y hecho so- cial}

El carácter "personal" 0 individual de la donación de órganos, en tanto que se realiza desde la intimidad del individuo, no desaparece necesariamente ni siquiera en aquellos supuestos en los que entre donante y receptor no existe relación directa ni conocimiento mutuo, ni aun cuando se intercalan intermediarios, como es el caso de la donación de cadáver. Pero la donación se hace para la sociedad y a petición de ésta, representada en la institución sanitaria, mediante programas de captación de donantes. Se convierte así en un acto social que, siguiendo la lógica de Durkheim², ejerce un efecto coercitivo sobre la conducta individual y vincula a sujetos abstractos, a un donante que ama la humanidad y a un receptor que encarna el sufrimiento del mundo, contra el que la sociedad lucha mediante su generosi$\operatorname{dad}^{1,3}$.

Siguiendo uno de los postulados de Levi-Strauss², la sociedad se funda en el intercambio, y la donación de órganos, como hecho social, es una combinación de intercambios en los que rige el principio de reciprocidad, del que dependen en gran medida las relaciones solidarias entre los individuos y los grupos. La donación de órganos actúa como un compromiso adquirido en términos morales que obliga a la reciprocidad, en términos de colectividad, no es individual. Los órganos se donan a la sociedad, representada por la institución, y no para nadie en concreto (salvo en el caso de la donación de vivo).
Para que la donación sea efectiva es preciso el intercambio entre quienes donan, quienes reciben y una tercera parte para que lo donado circule socialmente, creándose así el compromiso social2,4. Sobre este argumento se fundamentan muchos de los "mensajes" que lanzan las organizaciones responsables de la donación para estimular una atmósfera de donación $n^{5,6}$ :

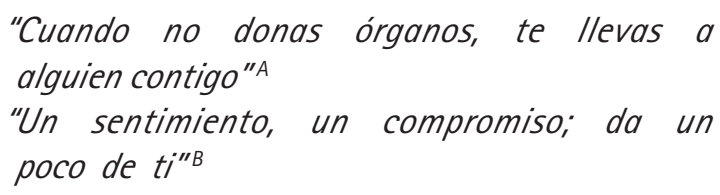

La reciprocidad es, según Kottak ${ }^{4}$, el intercambio entre personas socialmente iguales, y la clasifica en generalizada, la forma más pura de reciprocidad, característica de los intercambios entre personas estrechamente relacionadas - este sería el contexto de la donación de órganos entre familiares y el de las donaciones de vivos no emparentados, puramente altruistas (donaciones estas rechazadas por la mayoría de las sociedades por la incertidumbre legal, ética y psicológica que suscitan $)^{7}$-; reciprocidad equilibrada, la distancia social aumenta, aumentando la necesidad de devolución - este sería el contexto del "trasplante recíproco de vivo" (al paciente A le ofrece un riñón un familiar, pero el trasplante es médicamente inviable. Este familiar podría ofrecer un riñón al paciente $B$ sobre el acuerdo de que un familiar del paciente $B$ donara su riñón al paciente $A$ ) supuesto contemplado y regulado en algunos países (Reino Unido, EEUU) -, y por ultimo, la reciprocidad negativa, en la que la distancia social es la mayor de todas. En el caso de la donación de órganos de cadáver, la reciprocidad, por la distancia social de los actores, sería negativa, sin embargo las instituciones responsables de la donación se encargan de hacerla equilibrada o de lo contrario se perderían gran número de donantes.

La sociedad, legitimada e instituida la donación de órganos como elemento necesario para la efectividad del trasplante como terapia óptima y única de algunas enfermedades, desarrolla toda una serie de estructuras que tienen como finalidad garantizar la justicia e igualdad en el acceso a los órganos dona- 
dos, como pilares básicos para mantener la donación solidaria sobre el fundamento de la reciprocidad.

En aquellas sociedades en las que no se consigue garantizar esa justicia y equidad en el acceso a los beneficios de la donación, o en las que existe una falta de recursos e infraestructura y en las que las diferencias sociales están vinculadas a la propiedad individual, la reciprocidad desaparece y es sustituida por el mercado, dando paso a la donación retribuida y el tráfico de órganos.

\section{Donación de órganos y necesidad/ demanda social} La donación de órganos como concepto concreto es un acto social, legitimado como tal tras la necesidad social de órganos que se genera con la realización del primer trasplante exitoso. En ese momento, la sociedad comienza la elaboración de toda una serie de normas y reglas que garantizan el funcionamiento social y que convierten la donación en una institución.

Durante siglos, la sustitución de una parte del cuerpo por otra ha sido una quimera de la humanidad, hasta el punto de que muchos héroes mitológicos de antiguas civilizaciones fueron representados con atributos de varios seres. La primera muestra del viejo sueño de los trasplantes, a partir de un donante cadáver, la constituye una leyenda medieval, según la cual los santos Cosme y Damián amputaron la pierna del cadáver de un gladiador etíope para reemplazar la pierna gangrenada del diácono Justiniano.

Muy próximo a nuestra época, en el Romanticismo, la novela gótica también se ocupó de los trasplantes; prueba de ello es la primera obra de Mary Shelley, Frankenstein, publicada en 1818. Sus numerosas adaptaciones cinematográficas muestran la vigencia del mito de un ser creado a partir de cadáveres humanos.

En cualquier caso, todos estos ejemplos no son más que el reflejo de varios sueños de la humanidad: uno de ellos podría ser el deseo de dotar a las criaturas de cualidades que habitualmente no concede la naturaleza, y otro, quizás, el de crear vida a partir de la muerte.

La época propiamente científica de los trasplantes y que origina la demanda social de la donación de órga- nos empieza en el siglo $\mathrm{XX}$, aprovechando los avances en las técnicas de sutura vascular ${ }^{8}$. El pilar fundamental para desarrollar con éxito un programa de trasplante es la existencia paralela de un sistema de generación de órganos efectivo que permita trabajar con continuidad y en las mejores condiciones, y esto depende en gran medida de la convicción de la población en la necesidad de cooperar en la donación, y también de la motivación del personal sanitario y hospitalario.

\section{Motivaciones}

La edad, el sexo, la religiosidad y la formación son condicionantes personales que influyen sobre la conducta de la donación, como también influyen las necesidades colectivas, pasando por las necesidades institucionales, políticas y económicas.

Estudios realizados con el objetivo de analizar las características psicosociales de donantes y no donantes ${ }^{9-11}$ determinan que las causas de los fenómenos de donación y no donación no deben buscarse en variables intrapsíquicas (excepto para la autoestima, algo más baja entre donantes ${ }^{9}$ sino más bien en variables de carácter social y personal: presión para la donación (familiares o amigos que la necesiten), experiencia en el tema, conocer o no los mecanismos necesarios para convertirse en donante, oportunidades para hacerlo. El altruismo no parece una variable significativa para la distinción entre donante y no donante; el altruismo es más bien una forma de racionalizar los propios motivos de los donantes que una motivación absoluta.

A continuación, entre comillas, las impresiones de distintos entrevistados:

"... sí, soy donante, mi madre murió en diálisis...."

"soy donante de todo cuanto pueda ser donado porque mi padre recibió sangre de alguien, o tal vez de muchos, cuando lo necesitó"

"....antes de que los gusanos se lo coman, si puede ser de utilidad para alguien.... para que quiero un hígado o un riñón una vez muerto"

\section{Representaciones de la donación de órganos}

En general, las personas se sienten movidas a donar órganos por diferentes motivos que van a condicionar lo que para ellos representa la donación: 
desde el altruismo y la solidaridad genuina:

"...creo en la humanidad, en las personas y en la vida"

Los adjetivos que caracterizan la donación en este caso son: "generosidad", "altruismo", "solidaridad", "entrega".

la satisfacción de necesidades éticas, morales y sentimentales

"... moralmente me siento obligada, ¿acaso no entregó dios su cuerpo por nosotros?..."

En este caso, los adjetivos más característicos: "caridad", "justicia", "bondad"

presión familiar y social

"....mi hija llevaba toda su juventud en diálisis, necesitaba verla vivir... aunque te aclaro, 10 mío fue un acto de puro egoísmo, [...] necesitaba vivir, no seguir sintiendo la responsabilidad sobre mis espaldas".

En esto caso, la donación se relaciona con la vuelta a la vida y la liberación de la esclavitud que la diálisis "impone" también entre los familiares de los pacientes renales. Estos donantes son definidos fundamentalmente como: "solidarios", "sensibles", "razonables", "comprensivos".

como respuesta de autoestima

"....me costó tomar la decisión, pero me siento más valiosa ahora, y llevo el carné de donante siempre en mi cartera".

La donación es, en este caso, una necesidad de sentirse útil y valorado. La donación para este grupo de personas constituye un acto de "valentía".

como una necesidad socio-sanitaria

"...bueno, la verdad es que una vez muerta ya no necesitas nada, y son muchas las personas, incluso jóvenes como yo, que necesitan un riñón o un hígado..."

En general, son los jóvenes los que con mayor frecuencia se acercan a la donación por razones de pertenencia y participación social y suelen definirse como "personas adaptadas al mundo actual" y a sus necesidades, con adjetivos definitorios específicos: "realistas", "comprensivos", "maduros", "razonables".

\section{El rito de la donación}

Basándonos en la definición de rito como acto social que puede tener la función de crear una solidaridad temporal o permanente entre personas, formando una comunidad social, podemos hablar de las campañas de captación de donantes como verdaderos actos rituales. Cumplen una función integradora de los valores, una realidad moral que ejerce una influencia en las personas y una continuidad del sistema social.

Son varios los estudios que confirman la mayor efectividad de las compañas de promoción que congregan a las personas sobre la conseguida con carteles publicitarios colocados en hospitales u otros lugares públicos ${ }^{9,12}$.

La eficacia del rito de la donación no es sólo la consecución de donantes sino la transformación de estos o de sus familiares en grupos de presión para la donación.

\section{Trato e información, elementos facilitadores de la donación}

Cabe aquí destacar la demanda repetida por parte donantes y de familiares de más información sobre la donación, de un trato sensible durante el proceso de la donación, de la asignación de tiempo para la toma de decisiones, de seguimiento de las instituciones responsables en el periodo post donación, como elementos para conseguir que estas personas "iniciadas" se conviertan en "iniciadores". Cuando estas demandas no se satisfacen se convierten en elementos desmotivadores importantes y ocasionan sentimientos de arrepentimiento ${ }^{13}$ :

"no puedo decir que me hayan tratado mal, pero la figura estrella fue sin duda mi hermano (el receptor)"

"sí, el médico me preguntaba por mi herida, pero nadie se interesó por mí"

"sí, aceptamos la donación, pero después qué... parece que sólo les interesaba su cuerpo." 
Los donantes esperan de los demás la reciprocidad de su comportamiento en función de su nueva situación, reclaman una compensación social, un mínimo de información y de seguimiento en el proceso posterior a la donación:

"son todos gente a la que nada le importa... Ios órganos es todo por lo que el personal del hospital parece sentir interés. Después de tres meses, no hemos vuelto a tener noticias de ningún tipo. Al menos podrían contarnos que tal está el receptor."

\section{Factores socioculturales que condicionan la dona- ción de órganos}

La donación de órganos en la sociedad occidental está rodeada de toda una serie de mitos que tienen su origen en factores y fenómenos socioculturales que condicionan la conducta hacia la donación:

"yo no quiero que mi cuerpo sea mutilado"

En la sociedad actual el cuerpo se ha convertido en objeto y sujeto de culto, un culto que trasciende más allá de la vida y que tiene especial arraigo en sociedades con modelos de comportamiento social individualistas.

"Si sufro un accidente y el hospital sabe que soy un donante es probable que el doctor no quiera salvar mi vida"

Bajo esta declaración subyace el miedo a la confrontación con la muerte y una falta de información sobre el concepto de muerte cerebral.

"Mi religión no me permite la donación"

Ninguna religión prohíbe la donación. Las únicas religiones en las que no está permitido extraer las vísceras son el budismo y las derivadas o entroncadas en esa doctrina, como el sintoísmo, el taoísmo y el movimiento zen, pero no porque prohíban la donación, sino porque sus rituales ante la muerte, la impiden. Todas aquellas culturas, como la japonesa, que no conciben cuerpo y alma de forma independiente rechazan la donación como un acto de "profanación del cuerpo"
Otros factores socioculturales con consecuencias nefastas sobre la donación son:

- El tráfico de órganos, existente en países como Asia, Latinoamérica y Europa del Este, y mitos como el del "robo de órganos" motivado, muy posiblemente, por el miedo a las nuevas tecnologías.

- La inmigración: la divulgación en los medios de comunicación del alto porcentaje de extranjeros incluidos en las listas de espera nacionales y la divulgación, fundada o no, de la resistencia de estas minorías hacia la donación.

- El racismo en sus distintas variantes.

- La falta de coherencia institucional: el aspecto emico de la donación para la institución: llamar al altruismo y la solidaridad para ayudar a otros, se ve superado y anulado por la expresión etica: reputación de la institución trasplantadora, fama, estímulo del ego del cirujano, etc. suscitando dudas sobre la adecuación del proceso de asignación de órganos.

\section{Conclusiones}

La donación de órganos es un acto social individual, se realiza desde la intimidad del individuo y se expresa por y mediante la colectividad.

La donación de órganos, como hecho social, vincula a sujetos abstractos y ejerce un compromiso moral que obliga a la reciprocidad.

Las conductas de donación y no donación no deben buscarse en variables intrapsíquicas, salvo para la autoestima, sino más bien en variables de carácter social y personal.

La eficacia de la donación se mide no sólo por el número de donaciones sino por la transformación de los donantes y sus familiares en grupos de presión para la donación.

\footnotetext{
- Conviene aclarar el sentido académico de estos términos. La información que se obtiene en el trabajo de campo es el resultado de la interacción entre dos tipos de discursos: el etic, un discurso basado en la racionalidad ajena al grupo que se investiga, y el emic, discurso cuyo sentido está basado en el interior del grupo (Velasco y Díaz de Rada 1997: 35) (14)
} 